\title{
A Gamificação como Metodologia para o Desenvolvimento de Competências Gerais da BNCC
}

\author{
Jarles Tarsso Gomes Santos ${ }^{1}$, Cintia Reis de Oliveira ${ }^{1}$, Crisiany Alves de \\ Sousa $^{1}$, Charles Andryê Galvão Madeira ${ }^{1}$, José Guilherme da Silva Santa Rosa ${ }^{1}$ \\ ${ }^{1}$ Instituto Metrópole Digital (IMD) - Universidade Federal do Rio Grande do Norte \\ (UFRN) - CEP: 59.078-970 - Natal - RN - Brasil \\ jarlestarsso@gmail.com, cintia.reis@ifce.edu.br, \\ crisianyalvesegmail.com, charlesdimd.ufrn.br, \\ jguilhermesantarosalgmail.com
}

\begin{abstract}
The demotivation of the student is one of the main factors that lead to failure and high school dropout. In this sense, the classroom environment starts to demand changes, seeking to improve student motivation. One of the solutions used to overcome this obstacle is gamified environments, which bring elements of games to the school context without actually playing games. Therefore, this study seeks to intervene in a class that has a history of failure and school dropout, applying a gamified activity, aligned with the competencies of the $B N C C$. The results point to the possibility of improvement in student motivation and show that it is possible to use gamification to contemplate competences such as cooperation, collaboration, communication, conflict resolution, and leadership.
\end{abstract}

Resumo. A desmotivação do estudante é um dos principais fatores que acarreta a reprovação e evasão escolar. Nesse sentido, o ambiente de sala de aula passa a exigir mudanças, buscando atingir a motivação do estudante. Uma das possiveis alternativas utilizadas para tentar contornar esse empecilho é a dos ambientes gamificados, que trazem ao contexto escolar o emprego de elementos de jogos com o intuito de estimular os estudantes. Com base nisso, este estudo busca intervir na realidade de uma turma com histórico de reprovação e evasão, aplicando uma atividade gamificada, alinhada às competências da BNCC. Os resultados apontam para a possibilidade de melhoria no nível de motivação dos estudantes e mostram que é possivel usar a gamificação para contemplar competências tais como cooperação, colaboração, comunicação, resolução de conflitos, e espírito de liderança.

\section{Introdução}

O processo educacional, nas escolas públicas do Brasil, vem apresentando índices cada vez mais alarmantes de evasão. De acordo com o Censo Escolar (2017), mais de 11\% dos alunos de ensino médio abandonaram a escola, mostrando um aumento considerável em relação aos anos anteriores. Diniz e Quaresma (2015) apontam a desmotivação como uma das principais responsáveis por esses altos índices, levando o estudante a abandonar os estudos. Tapia e Fita (2015) complementam que a motivação constitui fator essencial para que se consiga alcançar os objetivos de aprendizagem, fazendo com que os estudantes alcancem suas capacidades esperadas. 
VIII Congresso Brasileiro de Informática na Educação (CBIE 2019)

Anais do XXV Workshop de Informática na Escola (WIE 2019)

Diversas estratégias buscam proporcionar ao estudante um ambiente escolar motivador, que o engaje nas atividades propostas. A gamificação, por exemplo, caracteriza-se como uma metodologia ativa, que busca inserir elementos e mecânicas de jogos no cenário educacional, porém sem usar efetivamente os jogos [Fadel et al. 2014]. De acordo com Zichermann e Cunninghan (2011), ao criar experiências gamificadas proporcionamos ao estudante experimentar vários elementos de jogos que podem causar impactos positivos nas suas tarefas. Os autores afirmam que as mecânicas de jogos, quando bem utilizadas, proporcionam respostas significativas para a motivação dos estudantes que participam do ambiente gamificado.

Tapia e Fita (2015) destacam dois tipos de motivação comuns aos estudantes: a motivação intrínseca e extrínseca. A motivação extrínseca ocorre no momento em que os estudantes recebem recompensas inesperadas e seu efeito não é duradouro. Já a motivação intrínseca diz respeito ao interesse despertado no estudante, fazendo com que ele sinta atração em continuar prosseguindo no estudo, ao perceber que cada nível lhe abre espaço para o conhecimento de novos conceitos. De acordo com Brito e Madeira (2017) elementos de jogos como pontos, medalhas e recompensas estimulam a motivação extrínseca, pelo seu efeito causado apenas enquanto o elemento é apresentado ao estudante. Na motivação intrínseca, o estudante possui estímulo devido a liberdade de escolha, criatividade e expressão.

Neste contexto, Coutinho e Lisbôa (2011) afirmam que a escola vem sofrendo diversas transformações, tornando necessário mudar a forma de ensino, que já não se pauta apenas em desenvolver o conhecimento referente a disciplinas presentes no currículo escolar. Agora, o papel da escola se volta principalmente para $o$ desenvolvimento de habilidades e competências pertinentes ao estudante, que serão importantes por toda a vida. De acordo com as autoras, o professor passa a exercer cada vez mais o papel de mediador, deixando de ser o detentor de todo o conhecimento. Além disso, desenvolver competências como criatividade, inovação e a capacidade de lidar com tamanha informação disponível, passam a ser um dos principais objetivos da escola.

A Base Nacional Comum Curricular (BNCC) vem ao longo dos anos tornando-se cada vez menos conteudista, definindo competências essenciais para cada etapa escolar. Competências como cooperação, empatia, comunicação, capacidade de resolução de conflitos e resiliência são indispensáveis à vida no século XXI e contribuem para o desenvolvimento integral do estudante, devendo ser incorporadas de forma transversal e integradora ao currículo escolar [Brasil 2018].

Partindo desse pressuposto, o presente estudo visa responder ao seguinte problema: como é possível usar a gamificação para motivar estudantes de uma turma do Ensino Médio, com dificuldades de aprendizagem, inserindo no contexto educacional algumas habilidades e competências gerais da BNCC?

Pois que, de acordo com os estudantes, há uma falta de motivação que ocorre devido à dificuldade em acompanhar todo o conteúdo apresentado, visto o acúmulo de atividades e obrigações da turma, que se insere no contexto da educação em tempo integral e possui 27 alunos regularmente matriculados. Além disso, alguns estudantes possuem histórico de evasão e reprovação, que contribui para a baixo autoestima no andamento dos estudos.

Buscando atuar sobre o problema, este estudo propõe uma tentativa de intervenção, contemplando um ambiente gamificado, com o intuito de alcançar o 
VIII Congresso Brasileiro de Informática na Educação (CBIE 2019)

Anais do XXV Workshop de Informática na Escola (WIE 2019)

desenvolvimento de algumas competências gerais previstas na BNCC, que sejam pertinentes aos estudantes, observando o nível escolar em que se encontram. Para a compreensão do problema, foi utilizada a metodologia ativa Design Thinking, que propõe uma abordagem centrada no ser humano, buscando definir e interagir com o problema, observando o contexto estudado [Brown 2009].

Com base nisso, é apresentada uma proposta didática com intuito de trazer ao ambiente escolar um momento motivador, que contribua para o desenvolvimento de competências como cooperação, colaboração, comunicação, resolução de conflitos, e espírito de liderança.

\section{Gamificação na Educação}

Para Fortunato e Teichner (2017) os jogos possuem a capacidade de despertar a curiosidade dos jogadores, induzindo-os a passarem horas entretendo-se. Os autores afirmam que um dos principais motivos para esse fenômeno, são os conhecimentos empregados da psicologia, sociologia e marketing, que contribuem para a elaboração de um jogo capaz de conquistar o usuário.

Devido a capacidade motivadora que os jogos proporcionam às pessoas, autores como Zichermann e Cunninghan (2011) passam a defender as possibilidades que a gamificação possui para resolver problemas em diversos segmentos. Na educação, inúmeros estudos abordam o uso de propostas didáticas utilizando gamificação, que não se restringe a uma área do conhecimento específica, possuindo um caráter interdisciplinar [Silva e Bax 2017]. De acordo com Fava (2014) é possível adicionar elementos de jogos em sala de aula, desde que o professor repense seus conteúdos e se desafie um pouco mais na tentativa de inovar.

Zichermann e Cunninghan (2011) destacam sete principais mecânicas de jogos que podem ser utilizadas para causar impactos significativos nos jogadores, que são os pontos, níveis, placar, distintivos, missões, integração e engajamento. Brito e Madeira (2017) acrescentam outros elementos que devem ser integrados ao ambiente gamificado, como a narrativa e a liberdade de escolha do aluno, que contribuem para motivação duradoura dos estudantes.

Alguns desses elementos são observáveis no cenário educacional. Afinal, o boletim pode ser atribuído a uma forma de pontuação, gerando recompensas e punições aos estudantes. Entretanto, apesar de um cenário propício a gamificação, os resultados tendem a mostrar o processo educacional desmotivador e enfadonho, enquanto os jogos motivam e divertem os jogadores [Fortunato e Teichner 2017].

\section{Competências e Habilidades da BNCC}

A Base Nacional Comum Curricular compreende competência como "mobilização de conhecimentos (...), habilidades (práticas, cognitivas e socioemocionais), atitudes e valores para resolver demandas complexas da vida cotidiana, do pleno exercício da cidadania e do mundo do trabalho" [Brasil 2018]. As competências gerais da BNCC apontam para uma formação integral do aluno, visando a construção do seu projeto de vida, o protagonismo juvenil e a continuidade dos estudos. 
VIII Congresso Brasileiro de Informática na Educação (CBIE 2019)

Anais do XXV Workshop de Informática na Escola (WIE 2019)

O documento ainda divide as fases escolar em áreas do conhecimento, atribuindo competências específicas para cada uma delas, que guiam o estudante a concretizar as competências gerais ao longo de toda sua vida escolar.

Para assegurar que as competências sejam desenvolvidas pelos estudantes, a BNCC as divide em habilidades, que buscam apresentar os conteúdos e conceitos que o discente deve desenvolver ao longo de sua trajetória escolar. As habilidades são divididas para cada componente curricular, devendo ser adaptadas ao contexto de cada instituição de ensino.

\section{Metodologia}

A criação da proposta de intervenção gamificada baseou-se na metodologia do Design Thinking, seguindo as fases de Imersão, Ideação e Prototipação. A abordagem do Design Thinking usa técnicas do designer e as ferramentas de inovação, relacionando as necessidades das pessoas com o que é tecnicamente possível [Brown 2008]. Nela, o designer parte em busca da compreensão sobre as necessidades das pessoas que estão sendo estudadas, buscando contribuir para melhorar o cenário [Brown 2010]. A abordagem do Design Thinking permite identificar problemas e gerar soluções, considerando problema qualquer tipo de prejuízo atribuído a um indivíduo, seja ele emocional, cognitivo ou estético [Vianna et al. 2012]. Desse modo, as fases propostas por essa abordagem foram contextualizadas para o cenário que trata este estudo, visando atuar sobre o processo de motivação dos estudantes que constituem o público-alvo da pesquisa.

De acordo com Vianna et al. (2012) o processo envolvendo o Design Thinking inicia-se com a fase de Imersão, dividindo-se em outras duas etapas: Imersão Preliminar e Imersão em Profundidade. Enquanto a primeira busca o aprofundamento no problema, identificando-o de forma clara, a etapa seguinte contribui para o entendimento das necessidades do público-alvo. Só então é possível entrar na fase de Ideação, na qual ocorre uma tempestade de ideias para solucionar o problema. Nesse momento é muito importante que a criatividade e as propostas sejam ouvidas por todos do grupo, a fim de encontrar a melhor solução. Por fim, a Prototipação busca desenvolver e por último validar a ideia elaborada.

\subsection{Caracterização dos sujeitos}

Os estudantes que participaram da proposta deste estudo compõem o segundo ano do ensino médio de uma escola pública no Estado da Paraíba. A escola em questão caracteriza-se como profissionalizante, oferecendo cursos técnicos integrados ao ensino médio. Os estudantes fazem parte do Curso Técnico em Informática e integram uma turma heterogênea, com faixa etária entre quinze e vinte e um anos. A turma possui estudantes de um nível socioeconômico considerado baixo e apresenta histórico de reprovações. Dentre os estudantes, dois são atendidos pela sala de Atendimento Educacional Especializado (AEE).

\subsection{Imersão}

Para a definição do problema, foi utilizada a observação no contexto de sala de aula e um questionário oral por parte do professor. Foi realizado um levantamento da frequência, bem como uma análise geral da turma, que através do diálogo entre alunos e o professor, comprovou a falta de aspectos estimulantes para a turma, visto que os estudantes 
VIII Congresso Brasileiro de Informática na Educação (CBIE 2019)

Anais do XXV Workshop de Informática na Escola (WIE 2019)

apresentaram resistência em realizar atividades propostas e em diversas ocasiões se reuniam para não irem à escola.

A observação, portanto, constatou aspectos prejudiciais ao rendimento escolar. Dentre eles podemos citar: baixo índice de frequência da turma, apresentando participação inferior a 30\% do total de estudantes em alguns dias letivos. Além disso, a turma apresenta rendimento acadêmico abaixo da média. De acordo com índices da instituição, a turma apresentou, no ano anterior, reprovação de $27 \%$ dos estudantes, estando acima da média apresentada pela escola (10\%).

Para a imersão do problema em profundidade, foi aplicado um questionário diagnóstico ${ }^{1}$, que obteve o total de 21 respostas, buscando quantificar o grau de motivação dos estudantes e a percepção da turma para o nível de aplicabilidade das competências gerais no ambiente de sala de aula. O resultado aponta que $66,7 \%$ dos estudantes dificilmente encontram motivação para as aulas e que $19 \%$ afirmam nunca ter motivação para ir à escola.

No que diz respeito às competências gerais da $\mathrm{BNCC}, 61,9 \%$ declararam que a cooperação acontece apenas em alguns momentos e 19\% afirmam não haver cooperação em sala de aula. A respeito dos conflitos, 33,9\% afirmam que ocasionalmente os mesmos são resolvidos entre a turma, enquanto $23,8 \%$ declararam que os conflitos nunca são resolvidos em sala.

A coleta inicial dos dados permitiu entender com maior profundidade o cenário vivido pelos estudantes em sala de aula, contribuindo para a elaboração de ideias que pudessem intervir na realidade estudada. Esse processo encontra-se descrito nas fases de Ideação e Prototipação.

\subsection{Ideação}

Durante o processo de brainstormings, em que as ideias foram debatidas entre os participantes, pesquisadores e estudantes puderam discutir e propor soluções, com o objetivo de obter insights que pudessem ser aplicados para a solução do problema. Essa etapa durou aproximadamente um mês e ocorreu com encontros semanais, que buscaram discutir as propostas elaboradas e alinhar a prática de gamificação ao objetivo final de estimular a aquisição de competências, bem como alcançar a motivação dos estudantes.

Nessa fase, foram discutidas soluções que conduzissem aspectos práticos e de engajamento dos estudantes. Em um primeiro momento discutiu-se acerca da possibilidade de relacionar os conteúdos estudados com aspectos ambientais e socioeconômicos, pois foi observado como pauta dos assuntos relevantes para o ensino médio no que diz respeito às competências da BNCC. Outro campo de ideias ocorreu na relação entre aspectos de sociabilidade e a formação de competências para o mercado de trabalho. Dada a relevância do tema e a caracterização da turma, que se constitui por alunos de formação técnica e, portanto, voltados para a ocupação profissional, optou-se por esse encadeamento de ideias.

Finalizados os encontros, foi identificado que o uso de jogos e técnicas de gamificação aliadas aos conteúdos didáticos, são ótimos artifícios para engajar

\footnotetext{
${ }^{1}$ Perguntas contidas no questionário, bem como os resultado em gráficos disponível em: http://bit.ly/2Lo2cBu.
} 
VIII Congresso Brasileiro de Informática na Educação (CBIE 2019)

Anais do XXV Workshop de Informática na Escola (WIE 2019)

ativamente os estudantes em sala de aula, proporcionando um ambiente de aprendizagem dinâmico e desafiador. Essas informações contribuíram para o desenvolvimento da proposta de intervenção, bem como a definição dos elementos de jogos que foram integrados a atividade.

\subsection{Prototipação}

Após avaliar o problema e discutir ideias de intervenção, chegou-se à sugestão de realizar uma dinâmica em grupos, buscando estimular algumas competências propostas pelo estudo. Optou-se por uma dinâmica que propõe a montagem de quebra-cabeças em grupos, visando aplicar técnicas de jogos voltadas para o contexto de sala de aula. A Tabela 1 apresenta a proposta gamificada, na qual cada etapa da dinâmica é descrita, juntamente ao resultado esperado quanto ao desenvolvimento cognitivo do estudante.

Tabela 1. Prototipação utilizada na proposta gamificada.

\begin{tabular}{|c|c|c|}
\hline Etapa & Descrição & $\begin{array}{l}\text { Resultados } \\
\text { Esperados }\end{array}$ \\
\hline $\begin{array}{l}\text { Material } \\
\text { utilizado }\end{array}$ & $\begin{array}{l}\text { - } 10 \text { Quebra-cabeças diferentes, com o total de } 30 \text { peças, cada; } \\
\text { - Cinco envelopes; } \\
\text { - Dispositivo para cronometrar tempo. }\end{array}$ & - \\
\hline $\begin{array}{l}\text { Divisão da } \\
\text { turma }\end{array}$ & Estudantes divididos em 5 grupos. & $\begin{array}{l}\text { Estimular a } \\
\text { socialização dos } \\
\text { estudantes. }\end{array}$ \\
\hline Preparação & $\begin{array}{l}\text { Antes da atividade: } \\
\text { - O professor/mediador deverá dividir dois quebra-cabeças para cada } \\
\text { envelope, retirando } 10 \text { peças de cada quebra-cabeça, de modo que } \\
\text { fiquem } 20 \text { peças restantes de cada um deles; } \\
\text { - As peças que foram retiradas anteriormente, deverão ser distribuídas } \\
\text { entre os demais envelopes, de modo que fiquem embaralhadas. } \\
\text { Durante a atividade } \\
\text { - Um membro de cada equipe deverá ser designado líder; } \\
\text { - O professor/mediador passará as instruções apenas para o líder de cada } \\
\text { equipe, que será responsável por comunicar as regras para sua equipe. }\end{array}$ & $\begin{array}{l}\text { Incentivar o espírito } \\
\text { de liderança. } \\
\text { Promover a } \\
\text { capacidade de } \\
\text { trabalhar em equipe e } \\
\text { seguir orientações. } \\
\text { Verificar como } \\
\text { ocorre a comunicação } \\
\text { entre o grupo e o } \\
\text { entendimento das } \\
\text { regras definidas. }\end{array}$ \\
\hline Regras & $\begin{array}{l}\text { - Cada equipe receberá um envelope contendo } 60 \text { peças de quebra- } \\
\text { cabeça; } \\
\text { - Existem peças que não são do interesse da equipe, que poderão ser } \\
\text { passadas para outra equipe; } \\
\text { - As equipes só poderão passar as peças que não forem do seu interesse } \\
\text { para o grupo que estiver à sua direita e só poderão receber do grupo que } \\
\text { está a sua esquerda; } \\
\text { - Poderá haver negociação de peças entre os grupos, porém, ambos } \\
\text { deverão ceder alguma peça; } \\
\text { - Não é permitido esconder peças que não forem do seu interesse, sob } \\
\text { risco de eliminação; } \\
\text { - Ganhará aquele que conseguir montar mais peças no tempo fornecido } \\
\text { (15 minutos); }\end{array}$ & $\begin{array}{l}\text { Desenvolver a } \\
\text { cooperação, } \\
\text { comunicação, } \\
\text { resolução de conflitos } \\
\text { e resiliência. }\end{array}$ \\
\hline
\end{tabular}


VIII Congresso Brasileiro de Informática na Educação (CBIE 2019)

Anais do XXV Workshop de Informática na Escola (WIE 2019)

A proposta apresentada foi desenvolvida com o intuito de subsidiar a aquisição de algumas competências gerais da BNCC, atreladas a mecânicas, componentes e dinâmicas de jogos, buscando alcançar a motivação dos estudantes. Costa e Marchiori (2016), destacam a relação existente entre dinâmicas, mecânicas e componentes de jogos como uma tríade aplicável aos estudos e desenvolvimento da gamificação.

As mecânicas de jogo se referem aos elementos mais específicos que levam às ações, orientando o jogador em uma direção desejada, enquanto os componentes são aplicações específicas, visualizadas e utilizadas na interface do jogo. Nesse contexto, as dinâmicas de jogos representam o mais alto nível de abstração de elementos do jogo e são os temas em torno do qual o jogo se desenvolve, mas que não fazem parte diretamente do jogo [Costa e Marchiori 2016]. A Tabela 2 ilustra as relações identificadas entre os elementos de jogos e as competências gerais, propostas durante a etapa de prototipação da intervenção desenvolvida.

Tabela 2. Relação entre elementos de jogos e competências gerais.

\begin{tabular}{|c|c|c|c|}
\hline $\begin{array}{c}\text { Competência } \\
\text { Geral }\end{array}$ & $\begin{array}{c}\text { Mecânica de } \\
\text { Jogo }\end{array}$ & $\begin{array}{c}\text { Componentes de } \\
\text { Jogo }\end{array}$ & Dinâmicas do Jogo \\
\hline Cooperação & $\begin{array}{c}\text { Aquisição de } \\
\text { recursos }\end{array}$ & Gráfico Social & Relacionamentos \\
\hline Colaboração & $\begin{array}{c}\text { Aquisição de } \\
\text { recursos }\end{array}$ & Times & Relacionamentos \\
\hline Comunicação & Transações & Times & Relacionamentos \\
\hline $\begin{array}{c}\text { Resolução de } \\
\text { Conflitos }\end{array}$ & Competição & Combate & Relações \\
\hline $\begin{array}{c}\text { Espírito de } \\
\text { Liderannça }\end{array}$ & Desafios & Níveis/Combate & Rentos \\
\hline
\end{tabular}

Fonte: adaptado de Costa e Marchiori (2016).

\section{Resultados e Discussão}

A aplicação da proposta de gamificação, na fase de prototipação, permitiu aos pesquisadores realizarem a observação dos impactos gerados nos estudantes durante a condução da atividade. Além disso, o questionário final ${ }^{2}$ permitiu que os estudantes apresentassem uma visão a respeito da sua identificação frente às competências trabalhadas, bem como demonstrassem o nível de motivação gerado.

O questionário abordou questões referente a cooperação, colaboração, mediação de conflitos, comunicação, espírito de liderança e a motivação gerada durante o momento gamificado. Todas as perguntas questionaram acerca do nível de percepção do estudante sobre cada competência e a respeito da motivação, contendo as seguintes opções de resposta: Ótimo, Bom, Regular e Ruim. O questionário foi respondido por um total de 21

\footnotetext{
${ }^{2}$ Resultado em gráficos disponível em: http://bit.ly/30Bc6TZ.
} 
VIII Congresso Brasileiro de Informática na Educação (CBIE 2019)

Anais do XXV Workshop de Informática na Escola (WIE 2019)

estudantes e o panorama geral acerca dos dados coletados pode ser observado na Figura 1.

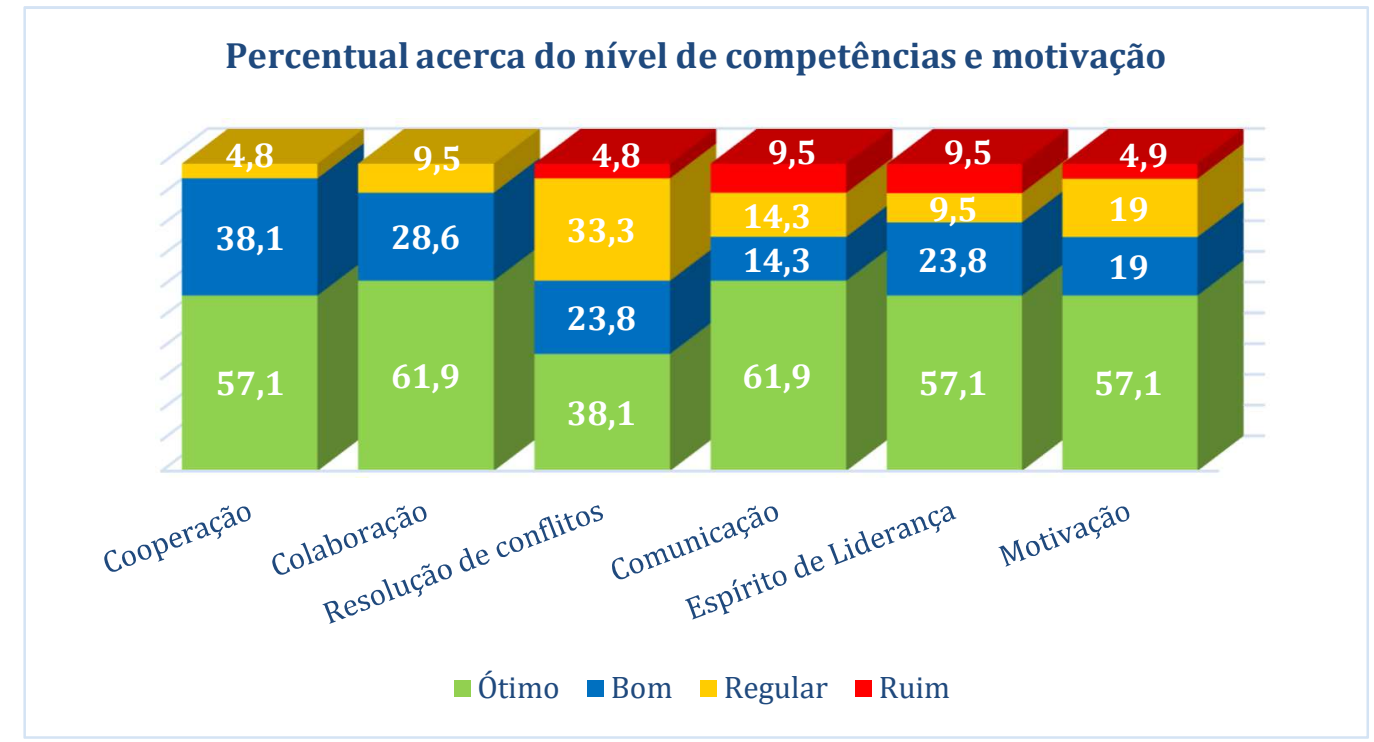

Figura 1. Percepção dos estudantes quanto ao nível de competências e motivação geradas durante a atividade.

Diante dos dados, é possível perceber que grande parte dos estudantes compreendeu o processo de cooperação exigido pela atividade, que ocorreu no momento em que eles precisaram montar as peças em conjunto, bem como necessitaram trabalhar em contato com as demais equipes, para garantir que as peças possam passar por todos os grupos. A BNCC aborda que a escola, durante a fase do ensino médio, deve permitir a construção de projetos pessoais e coletivos, que se embase em ações capazes de estimular a cooperação [Brasil 2018]. De fato, a atividade gamificada permitiu estimular o processo de cooperação, visto que todos os estudantes precisaram trabalhar juntos para a conclusão de um desafio comum a toda equipe.

A respeito da colaboração e espírito de liderança, a BNCC aponta como facilitadoras para que o estudante possa exercer uma postura empreendedora, capaz de inseri-lo em um cenário complexo e imprevisível [Brasil 2018]. O documento entende que essas competências são indispensáveis para a condução do projeto de vida do estudante, visando garantir uma cidadania ativa e a inclusão social. De acordo com Ferreira e Santos (2018) a gamificação permite o desenvolvimento de capacidades como liderança e a visão estratégia, contribuindo para a formação de um sujeito criativo e capaz de observar problemas no mundo real.

Com relação ao espírito de liderança, é possível perceber algumas avaliações negativas na opinião dos estudantes. Apesar de os resultados do questionário apontarem para um maior percentual variando entre Ótimo e Bom, as observações do mediador permitiram compreender a grande dificuldade do líder de cada equipe no repasse de informações para o restante dos estudantes. Mesmo com uma orientação clara quanto ao objetivo final da atividade (montar a maior quantidade de peças possíveis), alguns líderes não conseguiram mostrar de forma precisa à sua equipe. Durante a verificação do vencedor, umas das equipes contestou o fato de ter montado um dos dois quebra-cabeças fornecidos, enquanto uma equipe adversária foi superior, mesmo não conseguindo concluir nenhum dos dois quebra-cabeças por inteiro. 
Quanto à colaboração, os dados coletados apontam que a maior parte dos estudantes compreendeu a presença dessa competência durante a atividade, observada no momento em que os estudantes compreenderam que a divisão de tarefas poderia ser uma solução para concluir o desafio. Portanto, todos os grupos passaram a se dividir em funções, ficando cada indivíduo responsável pela realização de uma tarefa. Dessa forma, alguns estudantes focaram na montagem do quebra-cabeça, enquanto outros realizaram a negociação com os demais grupos.

No quesito resolução de conflitos, grande parte dos estudantes considerou sua presença em nível regular, durante a atividade. A BNCC contempla a resolução de conflitos entre as dez competências gerais para o estudante, durante sua fase escolar [Brasil 2018]. O documento ainda aponta que é no ensino médio que o estudante deve ser capaz de promover diálogo e soluções não violentas de conflitos.

Durante a atividade, foi possível perceber a grande dificuldade que os grupos tiveram para mediar os conflitos. Em diversas ocasiões, grupos invadiram o espaço alheio em busca de peças, sem que houvesse uma negociação correta. Além disso, houve recusa por parte de alguns estudantes para ceder peças, visando prejudicar as equipes adversárias. A figura do mediador foi constantemente requisitada para resolver problemas entre rivais, mesmo após a orientação sobre a não participação do mesmo.

\section{Considerações Finais}

Diante da proposta de alinhar elementos de jogos às competências de cooperação, colaboração, resolução de conflitos, comunicação e espírito de liderança, este estudo mostrou uma pequena possibilidade para o engajamento de estudantes dentro de um ambiente gamificado.

Com a aplicação da proposta gamificada, foi possível observar que os elementos de jogos trabalhados podem contribuir para trazer um momento de motivação e engajamento para os estudantes em sala de aula, permitindo que o professor capte alternativas para inserir demais conteúdos em um ambiente propício à aprendizagem.

Durante os 15 minutos que sucederam a atividade, todos os estudantes, sem exceção, estiveram engajados do primeiro ao último segundo. Esse dado pode apontar a capacidade que a atividade proposta demonstra em estimular a motivação do estudante, ao menos na primeira aplicação. Com as observações do mediador e a coleta de dados mediante questionário, percebe-se que todas as competências propostas foram em algum momento trabalhadas, apesar de não atingirem 100\% da turma.

Por se caracterizar uma proposta de gamificação em fase de prototipação, ainda é necessário realizar ajustes e acrescentar novos elementos de jogos como o crescimento de níveis, enredo e outros elementos capazes de melhorar a proposta apresentada e a percepção por partes dos estudantes em relação às competências abordadas.

Além disso, a proposta não permite uma aplicação a longo prazo sem que se torne repetitiva, havendo necessidade de realizar novas oficinas que viabilizem a formação de outras competências inerentes ao ambiente escolar, possibilitando a criação de um leque de opções aos professores. 
VIII Congresso Brasileiro de Informática na Educação (CBIE 2019)

Anais do XXV Workshop de Informática na Escola (WIE 2019)

\section{Referências}

Brasil. (2018). Base Nacional Comum Curricular: educação é a base. Brasília: MEC. $<$ http://basenacionalcomum.mec.gov.br/images/BNCC_EI_EF_110518_versaofinal_ site.pdf $>$. Acesso em 31 de maio de 2019.

Brito, A. L. S., Madeira, C. A. G. (2017). Metodologias gamificadas para a educação: uma revisão sistemática. In: Anais do XXVIII Simpósio Brasileiro de Informática na Educação (SBIE 2017), páginas 133-142.

Brown, T. (2008). Design thinking. Harvard Business Review, 86(6), p. 85-92.

Brown, T. (2010). Design Thinking - Uma metodologia poderosa para decretar o fim das velhas ideias. Rio de Janeiro: Elsevier.

Costa, A. C. S., Marchiori, P. Z. (2016). Gamificação, elementos de jogos e estratégia: uma matriz de referência. InCID: R. Ci. Inf. e Doc, 6(2), páginas 44-65.

Coutinho, C., Lisbôa, E. (2011). Sociedade da informação, do conhecimento e da aprendizagem: desafios para educação no século XXI. Revista de Educação, 18(1), páginas 5-22.

Diniz, C. S. (2015). Evasão escolar no Ensino Médio: causas intraescolares na visão dos alunos. Dissertação de Mestrado - Centro Universitário UMA, Guajajaras.

Fadel, L. M., Ulbricht, V. R., Batista, C. R., Vanzin, T. (2014). Gamificação na Educação. São Paulo: Pimenta Cultural.

Fava, R. (2014). Educação 3.0. São Paulo: Saraiva.

Ferreira, S. C., Santos, T. L. J. P. (2018). Gamificação e o ensino de suporte básico de vida: uma experiência com crianças em cenário não escolar. In: XVII SBGames, páginas 1353-1356.

Fortunato, I., Teichner, O. T. (2017). Gamificação aplicada ao plano de aula: elementos para potencializar o ensino. Revista Ensino Interdisciplinar, 3(9), páginas 380-386.

Silva, F. B., Bax, M. P. (2017). Gamificação na educação online: proposta de modelo para a aprendizagem participativa. Revista eletrônica de biblioteconomia e ciência da informação, 22(50), páginas 144-160.

Tapia, J. A., Fita, E. C. (2015). A motivação em sala de aula: o que é, como se faz. Tradução de Sandra Garcia. São Paulo: Edições Loyola.

Vianna, M. (2012). Design Thinking: inovação em negócios. Rio de Janeiro: MJV Press.

Zicchermann, G., Cunningham, C. (2011). Gamification by Design. Cadana: O'Reilly Media. 